\title{
First-in-man application of a novel therapeutic cancer vaccine formulation with the capacity to induce multi-functional $T$ cell responses in ovarian, breast and prostate cancer patients
}

Neil L Berinstein ${ }^{1}$, Mohan Karkada ${ }^{2,3}$, Michael A Morse ${ }^{4}$, John J Nemunaitis ${ }^{5}$, Gurkamal Chatta ${ }^{6}$, Howard Kaufman ${ }^{7}$, Kunle Odunsi ${ }^{8}$, Rita Nigam², Leeladhar Sammatur ${ }^{2}$, Lisa D MacDonald ${ }^{2}$, Genevieve M Weir $^{2,3}$,

Marianne M Stanford ${ }^{2,3}$ and Marc Mansour ${ }^{2 *}$

\begin{abstract}
Background: DepoVax ${ }^{\mathrm{TM}}$ is a novel non-emulsion depot-forming vaccine platform with the capacity to significantly enhance the immunogenicity of peptide cancer antigens. Naturally processed HLA-A2 restricted peptides presented by breast, ovarian and prostate cancer cells were used as antigens to create a therapeutic cancer vaccine, DPX0907.

Methods: A phase I clinical study was designed to examine the safety and immune activating potential of DPX0907 in advanced stage breast, ovarian and prostate cancer patients. A total of 23 late stage cancer patients were recruited and were divided into two dose/volume cohorts in a three immunization protocol.

Results: DPX-0907 was shown to be safe with injection site reactions being the most commonly reported adverse event. All breast cancer patients (3/3), most of ovarian (5/6) and one third of prostate (3/9) cancer patients exhibited detectable immune responses, resulting in a $61 \%$ immunological response rate. Immune responses were generally observed in patients with better disease control after their last prior treatment. Antigen-specific responses were detected in $73 \%$ of immune responders ( $44 \%$ of evaluable patients) after the first vaccination. In $83 \%$ of immune responders (50\% of evaluable patients), peptide-specific $T$ cell responses were detected at $\geq 2$ time points post vaccination with $64 \%$ of the responders (39\% of evaluable patients) showing evidence of immune persistence. Immune monitoring also demonstrated the generation of antigen-specific T cell memory with the ability to secrete multiple Type 1 cytokines.
\end{abstract}

Conclusions: The novel DepoVax formulation promotes multifunctional effector memory responses to peptidebased tumor associated antigens. The data supports the capacity of DPX-0907 to elicit Type-1 biased immune responses, warranting further clinical development of the vaccine. This study underscores the importance of applying vaccines in clinical settings in which patients are more likely to be immune competent.

Trial Registration: ClinicalTrials.gov NCT01095848

Keywords: Immunotherapy, Peptide, Montanide, DepoVax ${ }^{\text {TM }}$

\footnotetext{
* Correspondence: mmansour@imvaccine.com

${ }^{2}$ Immunovaccine Inc, Halifax, NS, Canada

Full list of author information is available at the end of the article
} 


\section{Background}

Cancer immunotherapy has demonstrated clinical benefit in recent clinical trials [1-4]; however, in order to achieve greater efficacy, several challenges must be addressed. These include, i) poor immunogenicity of the chosen peptides and/or vaccine platforms, ii) inappropriate functional polarity of induced responder $\mathrm{T}$ cells, iii) inefficient trafficking into or poor integrity of specific $\mathrm{T}$ effector cells within the tumor microenvironment, iv) presence of tumor induced immune regulatory cells and v) suboptimal patient selection and integration with standard of care treatments. We sought to develop a vaccine strategy to address many of these challenges.

Our novel cancer vaccine DPX-0907 contains a polynucleotide-based adjuvant and a universal $\mathrm{T}$ helper peptide, along with seven HLA-A2 restricted peptides derived from tumor-associated antigens. These antigens are involved in multiple, critical cancer pathways such as tissue invasion and metastasis (P5; Integrin $\beta 8$ subunit precursor, P14; Junction plakoglobin and P15; EDDR1), evading apoptotic cell death (P3; BAP31) and providing the ability to resist anti-growth signals (P7; Abl binding protein C3) [5-9], with resultant specific immune responses expected to reduce the chance for progression of tumor escape variants $[9,10]$. These peptides were among 16 described using mass spectrometry analysis of HLA-A2-bound peptides from HLA-A2 ${ }^{+}$ovarian cancer cell lines [5]. We have previously described and tested this vaccine candidate in preclinical models $[5,11]$. The vaccine-incorporated peptides are presented by $\mathrm{MHC}$ class I on the cell surface of breast, ovarian and prostate cancer cells, but not on normal cells [6]. Their inclusion in DPX-0907 yields an immunogenic vaccine in HLAA2 transgenic mice that promotes the activation of both Type $1 \mathrm{~T}$ cell responses, while minimizing the induction of regulatory mechanisms [11].

In order to enhance the potency of a peptide platform, we developed a novel vaccine platform called DepoVax ${ }^{\mathrm{TM}}$ [11], a liposome-in-oil platform containing stable components that does not require creation of an emulsion, simplifying the use of oil-based depot vaccines in the clinic. DepoVax can be custom-formulated with mixtures of $\mathrm{CD}^{+} \mathrm{T}$ cell peptide epitopes, a $\mathrm{T}$ helper epitope derived from tetanus toxoid [12], and an adjuvant of choice. The liposomes carry incorporated hydrophilic antigens and adjuvant directly into an oil medium such as Montanide ISA51 VG, entrapping all vaccine ingredients in a form amenable for efficient uptake and processing/presentation by antigen presenting cells (APCs). DepoVax-formulated vaccines can induce effective immune responses after single dose administration [11,13-15]. In the current report, we describe the safety and immunogenicity of a phase I trial of DPX-0907 in HLA-A2 ${ }^{+}$patients with advanced breast, ovarian and prostate cancer.

\section{Materials and methods}

\section{Patient population and trial design}

Specific eligibility criteria for each type of cancer were: i) ovarian cancer: patients with stage III or IV ovarian cancer with evidence of a complete or partial response by radiological imaging after front-line debulking surgery and platin-based cytotoxic therapy or patients with metastatic ovarian cancer, clinically or radiologically stable disease for greater than 3 months after completion of first-line therapy; ii) breast cancer: patients with stage IV breast cancer who had received at least one course of hormonal or cytotoxic therapy for metastatic cancer, had completed their course of cytotoxic therapy and had been off therapy with stable disease or better for $\geq 3$ months. Continued hormonal therapy was permitted; iii) prostate cancer: patients with rising PSAs or increases in measurable disease after at least one course of an accepted hormonal therapy and castrate testosterone levels $(<50 \mathrm{ng} / \mathrm{dL})$ or who had received previous courses of cytotoxic chemotherapy. Where applicable, patients with prostate cancer remained on anti-androgen therapy during the trial. All patients were positive for the HLA-A2 haplotype and met other standard inclusion /exclusion criteria with a life expectancy of at least 6 months.

Subjects received three subcutaneous injections of the DPX-0907 vaccine three weeks apart in the same upper thigh region, either at $0.25 \mathrm{~mL}$ (dose A) or $1.0 \mathrm{~mL}$ (dose B), according to the schedule shown in Additional file 1: Figure S1. The study was conducted in accordance with ethical guidelines of the Declaration of Helsinki. The protocol and patient-informed consent form received approval by individual Institutional Review Boards and ethics committees. Written informed consent was obtained for all patients.

\section{Vaccine formulation}

DPX-0907 contained seven MHC class I-presented peptides (P4, P5, P7, P13, P14, P15 and P3 corresponding to peptides from Topoisomerase II $\alpha$, Integrin $\beta 8$ subunit precursor, Abl-binding protein C3, TACE/ADAM 17, Junction plakoglobin, EDDR1 and BAP31 respectively) which were isolated from HLA-A $2^{+}$ovarian cancer cell line (Additional file 2: Table S1) [5]. The vaccine containing these synthetic peptides (Polypeptide Inc., formerly NeoMPS, San Diego, CA) and a T helper peptide epitope (modified tetanus toxin peptide, 830-844; AQYIKANSKFIGITEL; A16L) was formulated in a proprietary DepoVax formulation as described in published work [11]. The aqueous liposomal solution was sized to $120 \mathrm{~nm}$ particle size through extrusion, lyophilized and shipped to clinical sites along with a vial of Montanide ISA51 VG (SEPPIC, France) and the clinical kits were stored at $4^{\circ} \mathrm{C}$ until use. Just before use, the lyophilized 
vaccine cake was reconstituted in Montanide ISA51 VG for injection.

\section{Immune monitoring}

DPX-0907-induced immune responses in the peripheral blood of vaccinated patients were investigated at baseline (SD0) and following each of the three doses administered (SD21, three weeks after first dose; SD42, three weeks after second dose; SD73, a month after third and final vaccination). Peripheral blood mononuclear cells (PBMC) were frozen in liquid nitrogen tanks and were shipped in batches to National Immune Monitoring Laboratory or NIML, (Montreal, QC) for immunological assessment.

\section{Pentamer staining}

The following Pro5 ${ }^{\circledR}$ MHC-pentamers conjugated to PE were purchased from ProImmune (Oxford, UK): A*0201-NLVPMVATV (CMV), A*0201-SLYNTVATL (HIV), A*0201-FLYDDNQRV (P4), A*0201-YLIELIDRV (P13), A*0201-NLMEQPIKV (P14), A*0201-FLAEDALNTV (P15), A*0201-ALMEQQHYV (P5), A*0201ILDDIGHGV (P7) and A*0201-KLDVGNAEV (P3). PBMC from patients and healthy donors were thawed and rested overnight (12-18 h) in complete RPMI media and were analyzed directly (ex vivo) or after in vitro activation for 10 days in the presence of individual peptides from the vaccine $(10 \mu \mathrm{g} / \mathrm{mL}$ from day $0-3$ and $5 \mu \mathrm{g} / \mathrm{mL}$ from day 4-10) and IL-2 (10 IU/mL), IL-15 (10 ng/mL). The pentamer analysis consisted of staining the PBMC with pentamer at $4^{\circ} \mathrm{C}$, followed by a wash step, and staining for the surface markers CD3, CD8 and CD45RA in combination with a cell viability marker. This assay was validated before patient samples were analyzed and inter- and intra-assay variations were strictly controlled using the positive control CMV-pentamer and negative control HIV-pentamer. The $\mathrm{CD}^{+}{ }^{+} \mathrm{T}$ cells were selected from total live gated cells and were further separated into CD4 and CD8 T cells. The CD8 T cells were further analyzed based on CD45RA expression and pentamer positivity to discriminate between memory and naïve population. More than two-fold higher frequencies of pentamer-positive CD8 $\mathrm{T}$ cells compared to pretreatment baseline values were considered as positive responders to vaccine treatment. In addition, a staining frequency value of greater than two standard deviations above background staining by negative control HIVpentamer (range $0.00-0.03 \%$ ) or CD8 negative cells (range $0.02-0.06 \%$ ) were required to consider a sample a positive response. The limit of detection for this assay is $0.02 \%$ frequency of pentamer-specific cells.

\section{Intracellular cytokine staining}

Briefly, $10^{6}$ PBMC, after overnight resting, were stimulated for 1 hour with individual peptides and pools of peptides (with and without A16L) in the presence of anti-CD107a antibodies. Final A16L peptide concentration was $0.5 \mu \mathrm{g} / \mathrm{mL}$ and stimulations with peptide pool were done at $1 \mu \mathrm{g} / \mathrm{mL}$ (for each peptide). Experimental controls included unstimulated PBMC, PMA/Ionomycin and CEF (CMV/EBV/FLU) peptide pool stimulated PBMC. Protein secretion inhibitors (GolgiPlug ${ }^{\mathrm{Ts}} /$ GolgiStop $^{\mathrm{Ts}}$, BD Bioscience) were added after 1 hour of stimulation, and cells were incubated for an additional 5 hours at $37^{\circ} \mathrm{C}$ and $5 \% \mathrm{CO}_{2}$. Following in vitro stimulation, cells were washed and surface stained (CD8, CD27 CD3, CD4, CD45RA, CD107a and viability marker) followed by intracellular staining (IFN- $\gamma$, TNF- $\alpha$, IL-17, IL2 and IL-4) of fixed/permeabilized cells. For gating, a standard method was used where live cells were gated for CD3 positive T cells, and were then gated further to separate CD4 and CD8 T cells. The CD27 and CD45RA markers were then used, and cells phenotyped as naïve, central memory, effector memory and late differentiated T cells. Each of these populations was tested for intracellular cytokine production following peptide stimulation.

Labeled cells were acquired on a LSR II flow cytometer using the FACS DiVa software (BD Bioscience) and analyzed using FlowJo software. Multifunctional cytokine analysis was performed after stringent gating of each cytokine positive population. In addition, SPICE, a data mining software application, was used to analyze large FlowJo data sets from polychromatic flow cytometry and to organize the normalized data graphically. A positive cytokine response was defined as more than two-fold increase in the frequency of cytokine secreting cells following peptide-stimulation compared to corresponding non-stimulated cells. Furthermore, vaccineinduced changes were considered positive when such cytokine positive cell frequency was more than two-fold compared to pre-treatment samples and showed $\geq 0.05 \%$ frequency. The limit of detection of this assay is $0.01 \%$ of responder cells.

\section{IFN- $\gamma$ ELISpot}

IFN- $\gamma$ ELISpot was performed at Cellular Technology Limited (Shaker Heights, OH). Patient PBMC or nonvaccinated healthy control PBMC were plated at $3 \times 10^{5}$ cells per well in 96 well ELISpot plates. Cells were left unstimulated or stimulated with a range of indicated individual peptides $(10-100 \mu \mathrm{g} / \mathrm{mL})$ or with similar concentrations of the pooled DPX-0907 peptides for $24 \mathrm{~h}$. The optimum concentration of peptide for stimulation in this assay was $25-50 \mu \mathrm{g} / \mathrm{mL}$. PHA was used as a positive control stimulus. Antigen-specific induction of IFN- $\gamma$ was measured by capturing the cytokine with plate-bound antibodies followed by developing and counting the number of spot forming units (SFU) in each well using automated plate scanner. The limit of 
detection of this assay is $0.01 \%$ of cells that secrete cytokines upon stimulation.

\section{Results}

\section{Patient baseline characteristics}

A total of 23 cancer patients qualified to participate in the study based on inclusion criteria, and included 13 prostate cancer, 7 ovarian cancer and 3 breast cancer patients. One of the ovarian cancer patients in the dose $B$ group discontinued the study due to an unrelated serious adverse event (SAE) following a single vaccination, leaving a total of 22 patients with 11 patients in each of the dosage groups. Details on patient' age, sex, race, history and number of previous treatments for all patients enrolled are summarized in Additional file 2: Table S2. The prostate cancer patients had a median age of 65 years (range $54-76$ years) while breast cancer patients had a median age of 46 (range 44-61 years) and ovarian cancer patients had a median age of 49 years (range 48 to 67 years). Of note, most of the patients $(16 / 23,70 \%)$ had a history of $\geq 3$ anti-cancer treatments (cytotoxic/ hormonal/radiation) and 4 patients (including one patient who did not complete all three vaccinations) had received a previous immunotherapy (Avastin/Provenge, Table 1).

\section{Safety}

Of the 22 patients who were vaccinated with the full cycle (three injections) of DPX-0907, no dose limiting toxicities (DLTs) were reported. A summary of the reported adverse reactions that are possibly, probably or definitely related to the different dose levels of DPX0907 treatment is shown in Table 2. The most common adverse events were grade 1 and 2 injection site induration and erythema for both dose cohorts. A higher incidence of grade 2 injection site erythema, edema and pain were observed in patients receiving the $1.0 \mathrm{~mL}$ dose vaccine. Two grade 3 ulcerations and a single grade 3 cellulitis were reported after repeated immunizations with the $1.0 \mathrm{~mL}$ dose in the same vicinity. In one patient, this ulceration and cellulitis were reported 3 weeks after the third vaccination, which completely resolved by the next follow-up visit. In another patient, the ulceration was noted 6 weeks after the third vaccination, which improved to grade 1 by the next follow-up visit. At the 6 month follow up, most injection site reactions in patients had resolved to grade 1 . There were no vaccine related grade 3 or greater adverse events after three immunizations with the $0.25 \mathrm{~mL}$ dose. Overall, four SAEs unrelated to DPX-0907 were observed including: i) abdominal pain due to disease progression resulting in hospitalization and eventually death, ii) pneumonia resulting in hospitalization, iii) partial bowel obstruction due to disease progression resulting in hospitalization, and iv) urinary obstruction due to disease progression resulting in hospitalization. No clinical signs of autoimmunity were seen in any treated patient.

\section{Clinical results}

Since long-term monitoring was not included in the clinical plan, and only 5 of 22 patients completed the full 6 month follow up visit, the maximum time to progression period recorded in the study was 8-9 months starting from the day of a patients' first vaccination (i.e. SD0). Hence, patients who reached the 6 month followup visit and remained disease free at that time were assigned a time to progression of $>8$ to 9 months. A summary of disease status, treatment history, response to earlier treatments, and time to progression is summarized in Table 1. During the study period 14 patients progressed, most of whom had prostate cancer (10 of 14 patients). In addition, one prostate cancer patient died of progressive disease 3.5 months into this study. Information on disease progression is not available for the remaining two prostate cancer patients since they opted out of the study. In contrast, disease progression was reported for 2 of 3 breast cancer patients and only 2 out of 6 ovarian cancer patients. Based on the favorable response to previous treatment, the breast cancer and ovarian cancer patient populations were less likely to be compromised immunologically and thus were evaluated together. Among patients who completed follow up, 1 of 3 breast cancer patients and 4 of 6 ovarian cancer patients had a time to progression of >8-9 months. These patients were still within the median progression free survival period for their previous treatment, thus a clinical benefit of vaccination cannot be ascertained in this study. Two of the five breast/ovarian cancer patients were treated in the dose A cohort and three were treated with the dose $B$ vaccine.

\section{Immune monitoring}

An important secondary objective of this trial was to determine the magnitude and diversity of cell-mediated immune responses induced by vaccination against the 7 cancer-associated peptide epitopes included in DPX0907. This was measured primarily by MHC-pentamer staining for antigen-specific $\mathrm{CD}^{+} \mathrm{T}$ cells and multiparametric flow cytometry using the intracellular cytokine staining (ICS) assay. An exploratory ELIspot assay was performed on select samples. Although a total of 22 patients received the full cycle of vaccinations, the quality of PBMC and the recovery of cells following thawing were poor in 4 prostate cancer patient samples, leaving samples from 18 patients that were deemed 'evaluable' for immune analysis.

Due to the relative short duration of the trial and the limited number of vaccine doses that could be applied to 
Table 1 Age, disease status, stage, response to last therapy and clinical outcome for subjects receiving a complete set of three injections

\begin{tabular}{|c|c|c|c|c|c|c|c|}
\hline $\begin{array}{l}\text { Subject } \\
\text { ID }\end{array}$ & $\begin{array}{l}\text { Age } \\
\text { (years) }\end{array}$ & Treatment history & Stage & $\begin{array}{l}\text { Response to } \\
\text { Prior Treatment }\end{array}$ & $\begin{array}{l}\text { Dose } \\
(\mathrm{mL})\end{array}$ & $\begin{array}{l}\text { Immune } \\
\text { Response }\end{array}$ & $\begin{array}{l}\text { Time to Progression* } \\
\text { (months) }\end{array}$ \\
\hline \multicolumn{8}{|c|}{ Breast Cancer } \\
\hline $01-13$ & 44 & $\begin{array}{l}\text { cytotoxic therapy, hormonal therapy, } \\
\text { immunotherapy (Avastin), radiation }\end{array}$ & IV & SD & 0.25 & Yes & $2^{a}$ \\
\hline $04-06$ & 61 & concurrent hormonal therapy & IV & SD & 0.25 & Yes & $>8$ \\
\hline 04-19 & 46 & $\begin{array}{l}\text { cytotoxic therapy, concurrent } \\
\text { hormonal therapy, radiation }\end{array}$ & IV & SD & 1.0 & Yes & $2.5^{\mathrm{a}}$ \\
\hline \multicolumn{8}{|c|}{ Ovarian Cancer } \\
\hline $05-14$ & 50 & platinin-based cytotoxic therapy & III & $C R$ & 0.25 & Yes & $4^{a}$ \\
\hline 05-15 & 48 & platinin-based cytotoxic therapy & III & $C R$ & 0.25 & Yes & $5^{a}$ \\
\hline 02-01 & 49 & platinin-based cytotoxic therapy & III & $C R$ & 0.25 & No & $>9$ \\
\hline 05-07 & 54 & platinin-based cytotoxic therapy & III & $C R$ & 1.0 & Yes & $>8$ \\
\hline 02-09 & 67 & $\begin{array}{l}\text { platinin-based cytotoxic therapy, } \\
\text { immunotherapy (Avastin) }\end{array}$ & IV & $C R$ & 1.0 & Yes & $>8.5$ \\
\hline $01-22$ & 49 & platinin-based cytotoxic therapy & III & $C R$ & 1.0 & Yes & $>8$ \\
\hline \multicolumn{8}{|c|}{ Prostate Cancer } \\
\hline $03-17$ & 60 & hormonal therapy, anti-androgen therapy & Unknown & PD & 0.25 & Yes & $2^{a}$ \\
\hline 01-04 & 67 & $\begin{array}{l}\text { hormonal therapy, cytotoxic therapy, } \\
\text { anti-androgen therapy, immunotherapy } \\
\text { (Provenge), radiation }\end{array}$ & IV & PD & 0.25 & No & $2^{a}$ \\
\hline 02-05 & 63 & $\begin{array}{l}\text { ongoing hormonal therapy, cytotoxic } \\
\text { therapy, concurrent anti-androgen therapy }\end{array}$ & IV & PD & 0.25 & Unknown & $U E^{b}$ \\
\hline $03-16$ & 65 & $\begin{array}{l}\text { hormonal therapy, cytotoxic therapy, } \\
\text { anti-androgen therapy, radiation }\end{array}$ & IV & PD & 0.25 & No & $2.3^{a}$ \\
\hline 02-02 & 66 & $\begin{array}{l}\text { hormonal therapy, cytotoxic therapy, } \\
\text { anti-androgen therapy, radiation }\end{array}$ & IV & PD & 0.25 & Unknown & $5.7^{a}$ \\
\hline 01-03 & 76 & $\begin{array}{l}\text { hormonal therapy, anti-androgen } \\
\text { therapy, radiation }\end{array}$ & IV & SD & 0.25 & No & $U E^{b}$ \\
\hline $02-12$ & 54 & $\begin{array}{l}\text { hormonal therapy, concurrent } \\
\text { anti-androgen therapy, radiation }\end{array}$ & IV & SD & 1.0 & Unknown & $2.3^{a}$ \\
\hline 01-18 & 68 & $\begin{array}{l}\text { hormonal therapy, anti-androgen } \\
\text { therapy, radiation }\end{array}$ & IV & PD & 1.0 & Yes & $2.3^{a}$ \\
\hline $02-20$ & 64 & $\begin{array}{l}\text { hormonal therapy, anti-androgen } \\
\text { therapy, radiation }\end{array}$ & IV & Unknown & 1.0 & Unknown & $2.3^{a}$ \\
\hline $03-21$ & 74 & $\begin{array}{l}\text { hormonal therapy, anti-androgen } \\
\text { therapy, radiation }\end{array}$ & IV & PD & 1.0 & No & $2.3^{a}$ \\
\hline $04-10$ & 63 & $\begin{array}{l}\text { hormonal therapy, concurrent } \\
\text { anti-androgen therapy, radiation }\end{array}$ & IV & PD & 1.0 & Yes & $3.5^{c}$ \\
\hline 03-08 & 60 & $\begin{array}{l}\text { hormonal therapy, anti-androgen } \\
\text { therapy, radiation }\end{array}$ & IV & PD & 1.0 & No & $6.5^{\mathrm{a}}$ \\
\hline 02-11 & 68 & $\begin{array}{l}\text { hormonal therapy, anti-androgen } \\
\text { therapy, radiation }\end{array}$ & IV & PD & 1.0 & No & $7.3^{\mathrm{a}}$ \\
\hline
\end{tabular}

$C R$ complete response, $S D$ stable disease, $P D$ progressive disease, $U E$ unevaluable. *since study day 0 .

${ }^{\text {a } D i s e a s e ~ p r o g r e s s i o n ~ n e c e s s i t a t i n g ~ s o m e ~ o t h e r ~ t y p e ~ o f ~ t r e a t m e n t . ~}$

bithdrawal of consent.

'Death due to disease progression.

patients, an immune response was defined as a response to one or more vaccine antigens at one or more of the time points analyzed post-vaccination. Among the 18 patients evaluable for immune endpoints in this study, the highest frequency of positive immune responses was observed among the breast and ovarian cancer patients. All $3(100 \%)$ breast cancer patients and 5 of $6(83 \%)$ ovarian cancer patients responded to antigens included 
Table 2 Safety and reported adverse events, occurring in two or more subjects, which were possibly, probably or definitely related to DPX-0907 treatment

\begin{tabular}{|c|c|c|c|c|c|c|c|}
\hline \multirow[t]{2}{*}{ Toxicity } & \multicolumn{2}{|c|}{ Total No. of Patients } & \multicolumn{2}{|c|}{$0.25 \mathrm{~mL}$ Group } & \multicolumn{3}{|c|}{$1 \mathrm{~mL}$ Group } \\
\hline & $0.25 \mathrm{~mL}$ & $1 \mathrm{~mL}$ & Grade 1 & $\overline{\text { Grade } 2}$ & Grade 1 & Grade 2 & Grade 3 \\
\hline Injection site induration & 11 & 9 & 6 & 5 & 3 & 5 & 1 \\
\hline Injection site erythema & 8 & 10 & 6 & 2 & 5 & 4 & 1 \\
\hline Injection site pain & 3 & 8 & 1 & 2 & 3 & 5 & \\
\hline Injection site pruritis & 3 & 2 & 3 & & 1 & 1 & \\
\hline Injection site warmth & 2 & 2 & 1 & 1 & 1 & 1 & \\
\hline Injection site hematoma & 2 & & 2 & & & & \\
\hline Injection site edema & 1 & 4 & 1 & & 2 & 2 & \\
\hline Injection site discoloration & 1 & 2 & & 1 & 2 & & \\
\hline Injection site rash & 1 & 1 & 1 & & & 1 & \\
\hline Injection site urticaria & 1 & 1 & 1 & & & 1 & \\
\hline Injection site dry skin & 1 & 1 & 1 & & 1 & & \\
\hline Injection site ulceration & & 3 & & & 1 & & $2^{*}$ \\
\hline Pain & 3 & 1 & 2 & 1 & & 1 & \\
\hline Fatigue & 2 & & 1 & 1 & & & \\
\hline Fever & 1 & 2 & & 1 & 1 & 1 & \\
\hline Arthralgia & 1 & 1 & 1 & & 1 & & \\
\hline Myalgia & 1 & 1 & 1 & & 1 & & \\
\hline Anaemia & 1 & 1 & & 1 & & 1 & \\
\hline
\end{tabular}

*Appeared three or more weeks after of third injection and completely resolved.

in the vaccine for a combined immune responder rate of $89 \%$. Among prostate cancer patients, 3 of 9 (33\%) showed a positive immune response to vaccination. Taken together, 11 of 18 patients (61\%) showed measurable immune responses against one or more of the vaccine antigens (Table 3). While two patients' response were measurable only by MHC-pentamer testing and 3 patients were positive only using the ICS assay, 6 of 11 patients' responses were detectable by both the methods used. Immune responses were detectable as early as SD21 in 8 of 11 responders (73\% or $44 \%$ of evaluable patients) suggesting that just one immunization was sufficient to elicit specific $\mathrm{T}$ cell responses in these patients. In 7 of 11 responders (64\%, or 39\%, of evaluable patients), specific response to cancer antigens was observed at SD73, suggesting the persistence of immune memory in peripheral blood. The 18 patients evaluable for immune response were equally split between dose cohorts (Table 4). Five of $90.25 \mathrm{~mL}$ (dose A) vaccine recipients (56\%) and 6 of 9 patients (67\%) treated with $1.0 \mathrm{~mL}$ (dose B) vaccine were categorized as immune responders.

MHC-pentamer reagents incorporating individual peptides contained in DPX-0907 were used to detect specific $\mathrm{CD}^{+} \mathrm{T}$ cell responses in patient blood ex vivo or after a 10 day stimulation of $\mathrm{T}$ cells in vitro with individual peptides. While most patients required in vitro stimulation of PBMC to expand and detect multimer positive cells, it was possible to detect such specific $\mathrm{T}$ cells ex vivo in two patients (Table 4). The frequency of ex vivo detected cells was further expanded following in vitro culture.

Table 3 Immune outcome in DPX-0907-treated patients

\begin{tabular}{lll}
\hline Total patients recruited & & 23 \\
Full treatment received & & 22 \\
Evaluable & & 18 \\
Immune response (IR) & & \\
Positive IR in: & Breast cancer & $3 / 3(100 \%)$ \\
& Ovarian cancer & $5 / 6(83 \%)$ \\
& Breast/Ovarian & $8 / 9(89 \%)$ \\
& Prostate cancer & $3 / 9(33 \%)$ \\
& All patients & $11 / 18(61 \%)$ \\
& Dose A & $5 / 9(56 \%)$ \\
Positive IR after: & Dose B & $6 / 9(67 \%)$ \\
& 1 vaccination & $8 / 11(73 \%)$ \\
& 2 vaccinations & $2 / 11(18 \%)$ \\
Positive IR at: & 3 vaccinations & $1 / 11(9 \%)$ \\
& 1 time point & $2 / 11(18 \%)$ \\
& 2 time points & $7 / 11(64 \%)$ \\
Existing IR at: & 3 time points & $2 / 11(18 \%)$ \\
\hline
\end{tabular}


Table 4 The Dose A and B vaccine recipients who responded to DPX-0907 vaccination and their immune response to vaccine antigens

\begin{tabular}{|c|c|c|c|c|c|c|c|}
\hline \multirow[t]{2}{*}{ PatientID } & \multirow[t]{2}{*}{ Cancer Type } & \multirow[t]{2}{*}{ Vaccine Dosage } & \multicolumn{2}{|l|}{ MHC Pentamer } & \multicolumn{3}{|c|}{ ICS - Flow cytometry } \\
\hline & & & Antigen Positive & Study day Positive & Positive Stimulus & Study day Positive & Multi-cytokine Positive \\
\hline $04-06^{a}$ & Breast & $0.25 \mathrm{~mL}$ & P5 P15 & 21,4242 & P5 Pool & 4242 & Yes Yes \\
\hline $01-13^{b}$ & Breast & $0.25 \mathrm{~mL}$ & None & NA & Pool & 21 & Yes \\
\hline $05-14^{b}$ & Ovarian & $0.25 \mathrm{~mL}$ & P4 & 21,42 & Pool & $21,42^{c}$ & Yes, $\mathrm{No}^{\mathrm{c}}$ \\
\hline $05-15^{b}$ & Ovarian & $0.25 \mathrm{~mL}$ & P3 P7 P13 & 737373 & None & NA & No \\
\hline $03-17^{b}$ & Prostate & $0.25 \mathrm{~mL}$ & None & NA & Pool & $21^{c}, 73$ & $\mathrm{No}^{c}$, Yes \\
\hline $04-19^{b}$ & Breast & $1.0 \mathrm{~mL}$ & None & NA & Pool & 42,73 & Yes, Yes \\
\hline $05-07$ & Ovarian & $1.0 \mathrm{~mL}$ & P15 & 73 & Pool & 21 & Yes \\
\hline 02-09 & Ovarian & $1.0 \mathrm{~mL}$ & P5 P3 & 42,7342 & None & NA & No \\
\hline $01-22^{b}$ & Ovarian & $1.0 \mathrm{~mL}$ & P5 & 21,73 & Pool & $21,42^{c}, 73^{c}$ & Yes, $\mathrm{No}^{c} \mathrm{No}^{\mathrm{c}}$ \\
\hline $04-10^{a}$ & Prostate & $1.0 \mathrm{~mL}$ & P5 P7 P15 & $21,424221,42$ & P13, P15, Pool & $4242^{c} 42$ & Yes $\mathrm{No}^{c}$ Yes \\
\hline $01-18^{b}$ & Prostate & $1.0 \mathrm{~mL}$ & P4 P7 & $4221,42,73$ & Pool & $21^{c}, 42^{c}, 73^{c}$ & $\mathrm{No}^{c}, \mathrm{No}^{c}, \mathrm{No}^{c}$ \\
\hline
\end{tabular}

${ }^{\mathrm{a}} \mathrm{MHC}$-multimer positive CD8 T cells were also detected ex vivo in these patients: Subject 04-06, P5 (0.12\% staining frequency) on SD42; Subject 04-10, P5 on SD21 $(0.11 \%)$ and on SD42 (0.23\%).

${ }^{\mathrm{b}} \mathrm{PBMC}$ from these patients were tested against pooled peptides only in ICS assay.

${ }^{\mathrm{C}} \mathrm{T}$ cells from PBMC at the indicated study day produced detectable levels of one of the cytokines tested (IFN- $\gamma$, TNF- $a$, IL-2).

Vaccination with DPX-0907 induced specific response against 6 of 7 tumor-associated peptides (all except P14; Table 4). The most frequent responses were seen against peptide P5, followed by P7 and P15. Five of 11 responding patients $(45 \%$ or $28 \%$ of evaluable patients) were positive for responses to two or more peptides contained in DPX-0907.

Among 11 responders in this study, 8 patients $(73 \%$ or $44 \%$ of evaluable patients) were positive in MHCpentamer testing, with two-fold or higher increase in the frequency of specific $\mathrm{CD} 8^{+} \mathrm{T}$ cells compared to baseline values. In some instances, the increase was $>50$-fold at post-vaccination time point compared to SD0 (Additional file 2: Table S3, data shown as fold-increase over baseline). Due to low level responses seen ex vivo, in vitro expansion using antigen peptides and cytokines was necessary in most patients; however, responses seen ex vivo were reproduced following in vitro activation. Some patients exhibited pre-existing immune responses (>two-fold higher than background control) and in some instances the vaccination stimulated expansion of these responses (Additional file 1: Figure S2). Sequential changes in the frequency of antigen-specific $\mathrm{T}$ cells at pre-vaccination baseline and at different postvaccination study days are shown in Figure 1. Although the peak response occurred on different post-vaccination days for different responders, in almost all patients the frequency of such cells remained higher at SD73 compared to SD0. Results from three representative responders identified by the MHC-pentamer assay, with

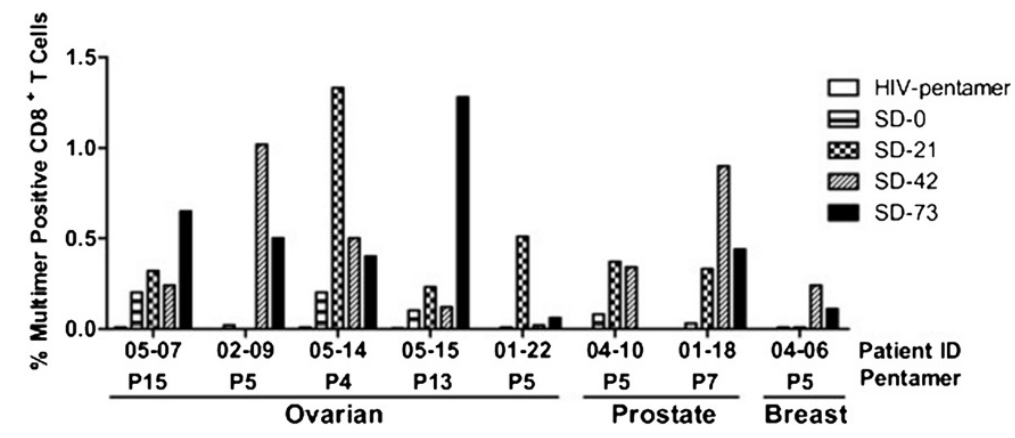

Figure 1 The generation of antigen-specific $\mathrm{CD}^{+} \mathrm{T}$ cells in DPX-0907 vaccinated ovarian, prostate and breast cancer patients. Patient PBMC were stimulated with indicated peptides in vitro as described in Materials and Methods. Cells were stained with corresponding MHCpeptide pentamer reagents to detect CD8 ${ }^{+}$T cells with peptide-specific TCR repertoire. HIV-pentamer served as a negative control (patients prescreened for being HIV negative) and CMV-specific pentamer was used on a known CMV-positive donor PBMC as internal positive control for the assay (data not shown). Samples from all study time points were run simultaneously in the assay for each patient. Data represented as percentage of live gated $\mathrm{CD}^{+} \mathrm{CD} 8{ }^{+}$cells that were positive for pentamer staining. The background staining on CD8 negative cells $(0.02-0.06 \%)$ has been subtracted from the values shown and the values for control HIV-pentamer staining were in the range of 0.00 to $0.03 \%$ for all patients. 
distinct $\mathrm{CD}^{+}{ }^{+}$pentamer ${ }^{+}$double positive cells, are shown in Additional file 1: Figure S3, with the data representing actual percentage frequency of $\mathrm{CD}^{+} / \mathrm{CD}^{2} 5 \mathrm{RA}^{-} /$multi$\mathrm{mer}^{+}$(antigen-experienced memory) cells.

The ICS assay allows a broader analysis of functionally relevant antigen-specific $\mathrm{T}$ cells following vaccination. ICS assays were performed with pools of peptides in most patient samples $(\mathrm{n}=10$ for pooled peptides and $\mathrm{n}=8$ where individual peptides were tested along with the pool of peptides) due to limited numbers of available PBMCs. Multi-parametric flow cytometry was performed on patient PBMC to identify the type of responding $\mathrm{T}$ cells (Total CD8; central and effector memory CD8 cells) along with their ability to simultaneously secrete Th1 type protective cytokines, namely IFN- $\gamma$, TNF- $\alpha$ and IL-2. The data from cells/peptides from responding patients have been presented (Tables 4 and 5) and the data indicate $\mathrm{T}$ cells are producing multiple cytokines at the single cell level. Among eleven immune responders, nine $(82 \%$, or $50 \%$ of evaluable patients) were positive in the ICS assay with a two-fold or higher increase in the frequency of one or more cytokine secreting $\mathrm{CD}^{+} \mathrm{T}$ cells compared to baseline values (Table 5). Central memory $\mathrm{CD}^{+} \mathrm{T}$ cells $\left(\mathrm{T}_{\mathrm{CM}}, \mathrm{CD} 45 \mathrm{RA}^{-} \mathrm{CD} 27^{+}\right)$were detected in these patients suggesting that the vaccine induced antigen-specific memory responses. Cytokine positive cells were more frequent in the $\mathrm{T}_{\mathrm{CM}}$ compartment than among total $\mathrm{CD}^{+} \mathrm{T}$ cells (data not shown), in keeping with previous activation of $\mathrm{T}_{\mathrm{CM}}$ cells. IFN- $\gamma$ secreting effector memory cells $\left(\mathrm{T}_{\mathrm{EM}}, \mathrm{CD} 45 \mathrm{RA}^{-} \mathrm{CD} 27^{-}\right)$ were also detected occasionally (data not shown), but multi-functional $\mathrm{T}_{\mathrm{EM}}$ cells were not a significant feature of the immune responses detected at the specified timepoints.

Multi-functional $\mathrm{T}$ cells expressing IL-2 along with IFN- $\gamma$ and TNF- $\alpha$ (Table 5) were detected in some patients. Three representative cancer patients whose samples demonstrate increased cytokine secretion following peptide stimulation are shown in Additional file 1: Figure S2.

Multifunctional $\mathrm{T}$ cells, as determined by the secretion of more than one cytokine simultaneously, were

Table 5 The generation of multi-functional T cells in patients who responded to vaccination with DPX-0907

\begin{tabular}{|c|c|c|c|c|c|c|c|}
\hline \multirow[t]{3}{*}{ Patient ID } & \multirow[t]{3}{*}{ Indication } & \multirow[t]{3}{*}{ Vaccine Dosage } & \multicolumn{5}{|c|}{ Antigen- specific Intracellular cytokine staining } \\
\hline & & & \multirow[t]{2}{*}{$\mathrm{CD8}^{+} \mathrm{T}$ cell population } & \multirow[t]{2}{*}{ Multi-cytokine positivity } & \multicolumn{3}{|c|}{ Cytokines } \\
\hline & & & & & $\mathrm{IFN} \gamma$ & TNFa & $\mathrm{IL}-2$ \\
\hline \multirow[t]{4}{*}{$04-06^{a}$} & Breast & $0.25 \mathrm{~mL}$ & Total & Double & + & + & - \\
\hline & & & Total & Triple & + & + & + \\
\hline & & & $\mathrm{T}_{C M}$ & Double & + & + & - \\
\hline & & & & Triple & + & + & + \\
\hline \multirow[t]{2}{*}{$01-13^{a}$} & Breast & $0.25 \mathrm{~mL}$ & Total & Double & + & + & - \\
\hline & & & $\mathrm{T}_{C M}$ & Double & + & + & - \\
\hline \multirow[t]{4}{*}{ 05-14 } & Ovarian & $0.25 \mathrm{~mL}$ & Total & Double & + & + & - \\
\hline & & & Total & Triple & + & + & + \\
\hline & & & $\mathrm{T}_{\mathrm{CM}}$ & Double & + & + & - \\
\hline & & & $\mathrm{T}_{\mathrm{CM}}$ & Triple & + & + & + \\
\hline 03-17 & Prostate & $0.25 \mathrm{~mL}$ & Total & Double & + & + & - \\
\hline \multirow[t]{2}{*}{ 04-19 } & Breast & $1.0 \mathrm{~mL}$ & $\mathrm{~T}_{C M}$ & Double & + & + & - \\
\hline & & & $\mathrm{T}_{C M}$ & Triple & + & + & + \\
\hline \multirow[t]{2}{*}{ 05-07 } & Ovarian & $1.0 \mathrm{~mL}$ & Total & Double & + & + & - \\
\hline & & & $\mathrm{T}_{\mathrm{CM}}$ & Double & + & + & - \\
\hline $01-22^{a}$ & Ovarian & $1.0 \mathrm{~mL}$ & Total & Double & - & + & + \\
\hline \multirow[t]{3}{*}{ 04-10 } & Prostate & $1.0 \mathrm{~mL}$ & Total & Double & + & + & - \\
\hline & & & Total & Double & + & - & + \\
\hline & & & Total & Triple & + & + & + \\
\hline \multirow[t]{4}{*}{$01-18^{a}$} & Prostate & $1.0 \mathrm{~mL}$ & Total & Single & + & - & - \\
\hline & & & Total & Single & - & + & - \\
\hline & & & Total & Single & - & - & + \\
\hline & & & $\mathrm{T}_{\mathrm{CM}}$ & Single & + & - & - \\
\hline
\end{tabular}

\footnotetext{
${ }^{a}$ These patients also showed the presence of IFN- $\gamma$ secreting $T_{E M}$ cells.
} 
demonstrated in nearly all responding patients within their total $\mathrm{CD}^{+}$and/or $\mathrm{CD}^{+} \mathrm{T}_{\mathrm{CM}}$ cell compartments. Four patients were positive for triple cytokine secreting multi-functional $\mathrm{CD}^{+} \mathrm{T}$ cells following vaccine treatment. Vaccine dosage did not influence the induction of multi-functional $\mathrm{T}$ cells, but the effect of dose is difficult to directly ascertain with this small sample size. Two examples of patients showing multi-functional $\mathrm{CD}^{+} \mathrm{T}$ cells are shown in Additional file 1: Figure S4. The presence of triple positive cells, induced only after vaccination, suggests that DPX-0907 was responsible for inducing multi-functional, anti-tumor effector cells. In addition, other cytokines such as IL-17, IL-4 and degranulation marker CD107a were also tested in the ICS assay. While there were no differences seen in the expression of IL-4 and IL-17 in our patient population throughout the treatment period, at least four patients showed expression of CD107a in combination with IFN- $\gamma$, TNF- $\alpha$ or both (data not shown).

As part of the ICS assay, the response of $\mathrm{CD} 4^{+} \mathrm{T}$ cells to the $\mathrm{T}$ helper epitope (A16L) included in DPX-0907 was also examined. Seventeen of our evaluable patient samples were tested in total, with nine PBMC samples tested with $\mathrm{A} 16 \mathrm{~L}$ alone and PBMC from eight patients were tested with a pool of DPX-0907 peptides, with or without the inclusion of A16L. In 13 patients $\mathrm{CD}^{+} \mathrm{T}$ cell responses were detected by ICS, including multiple cytokine secretion and four patients were considered non-responders. Interestingly, two patients exhibited both pre- and post-vaccination responses to A16L while 11 patients had a CD4 response to A16L postvaccination only. In addition, all nine patients who demonstrated positive cytokine responses in their $\mathrm{CD}^{+}$ $\mathrm{T}$ cell compartment by ICS also displayed positive response to $\mathrm{A} 16 \mathrm{~L}$ in their $\mathrm{CD}^{+} \mathrm{T}$ cell compartment. In contrast, four patients showed $\mathrm{CD} 4^{+} \mathrm{T}$ cell responses to A16L without a concurrent $\mathrm{CD}^{+} \mathrm{T}$ cell cytokine response.

For most patients, there were insufficient numbers of PBMCs collected to conduct further confirmatory immune assays. However, for two patients that were considered immune responders by both pentamer and ICS assays, there were sufficient PBMC to also test immune responsiveness using an IFN- $\gamma$ ELISpot assay. Although this assay was not a primary portion of the immune monitoring strategy, it afforded the opportunity to further confirm immune responses in these two patients. The ELISpot confirmed the responses seen in the ICS assays for both patients (Table 4, Additional file 1: Figure S5), in that peptides/pools that induced the production of multiple cytokines in the ICS assay also induced the production of IFN- $\gamma$ by ELISpot. Interestingly, an immune response to P13 peptide was detected in the ELISpot assay for patient 04-06, but no such response was recorded in the $\mathrm{MHC}$-pentamer assay. Conversely, an immune response to $\mathrm{P} 4$ peptide was detected by the MHC-pentamer assay for patient 05-14 and not detected by ELISpot. No non-specific IFN- $\gamma$ immuno-spots were seen in non-vaccinated healthy controls PBMC in response to DPX-0907 antigens, even at 10-fold higher antigen concentrations.

\section{Discussion}

The purpose of this study was to determine the safety and immunologic efficacy of DPX-0907, a peptide vaccine incorporating a novel carrier and adjuvant formulation. The delivery system, DepoVax, is a liposome-in-oil platform designed to efficiently entrap hydrophilic antigens and adjuvant directly in the oil medium Montanide ISA51 VG without the need for emulsification. DepoVax attracts APCs to the site of vaccination, facilitating antigen cross-presentation in $\mathrm{MHC}$ class $\mathrm{I}$ to $\mathrm{CD}^{+} \mathrm{T}$ cells [11]. As a peptide-based vaccine, DPX-0907 has the advantages of easy manufacture and a favorable safety profile [16]. The formulation itself has the additional advantages of long term stability, easy storage and an easy to use reconstitution method that does not require emulsification.

The primary endpoint of safety was achieved in this first-in-man study. Repeated administration of DPX0907 did not result in any dose limiting toxicities or serious adverse events related to vaccine treatment. The most frequent side effects were grade 1-2 injection site erythema and induration, consistent with other vaccines that incorporate Montanide ISA51 VG as the carrier medium [17-19]. There was no relationship between immune responses and the grade or frequency of site of injection reactions. When $0.25 \mathrm{~mL}$ (dose A) is compared to other vaccines that incorporate antigens in Montanide ISA51 VG emulsion with a similar oil content, DPX0907, not requiring emulsification, results in lower reports of pain and no reports of grade 3 induration and swelling [19]. However, we did note greater frequency of pain and edema, and the presence of grade 3 induration, erythema and transient ulceration in patients receiving multiple injections at the dose B (1.0 mL) of DPX-0907. Though the adverse events seen at the $1.0 \mathrm{~mL}$ dose were largely transient in nature, any further studies with DepoVax-formulated vaccines will likely contain no more than $0.5 \mathrm{~mL}$ of diluent.

The secondary endpoint was evaluation of antigenspecific immune responses to DPX-0907. DPX-0907 vaccination resulted in the activation of antigen-specific $\mathrm{T}$ cell responses in $61 \%$ of evaluable patients. There were no differences (as measured by the frequency, magnitude or quality of specific $\mathrm{T}$ cell responses) observed in patients entered on either of the dose tiers (data not shown), supporting the lack of a vaccine dose/immune 
response relationship as reported by others [20-22]. However, other studies have demonstrated dose dependent immune responses in patients vaccinated with peptide antigens $[23,24]$. This discrepancy may be related to the antigen, formulation, peptide/protein length (and subsequent requirement for antigen processing), adjuvant, vaccination regimen and patient population used in these studies. The immune responses in this study were rigorously documented with state of the art antigen-specific immune monitoring and consistent results were generally seen with different immune monitoring assays.

DPX-0907 generates rapid and sustained immune responses [11]. Many patients generated immune responses after the first vaccination and had detectable immune responses at two or more time points post DPX0907 vaccination. Responses could also be detected for least one month after the completion of the vaccination cycle, consistent with our preclinical data. This data compares favorably with other clinical trials in similar patient populations and was particularly favorable for breast and ovarian cancer patients. Morse et al [6] recently reported a phase I cancer vaccine study in ovarian and breast cancer patients targeting 12 antigens using MHC class Irestricted peptides, including the seven peptides used in DPX-0907 [5,6]. In that study, the peptides were formulated in a highly adjuvanted GM-CSF/Montanide ISA51 VG emulsion. The study demonstrated a 64\% (9 of 14 patients) $\mathrm{T}$ cell response rate by ELISpot, after 3-10 injections of vaccine [6]. A similar level of $\mathrm{CD}^{+} \mathrm{T}$ cell responses was seen in patients with epithelial ovarian cancer using NY-ESO1 peptides or a mix of tumor associated antigen peptides, also following at least 2-5 vaccinations [25-27]. DPX-0907 induced a similar immune response rate with one vaccination (56\%) and a higher immune response rate after three vaccinations (89\%) in similar patient populations. It is not clear in the vaccine trials mentioned above if these vaccines could generate immune responses after one vaccination and multifunctional $\mathrm{T}$ cell responses were not documented.

"Multi-functional" $\mathrm{T}$ cells, secreting a diverse array of cytokines in response to cognate antigen, have been increasingly associated with host protection in preclinical vaccine and tumor immunotherapy models and in HIVinfected patients [28-31]. Our finding that the majority of patients responding to DPX-0907 generate such multifunctional $\mathrm{T}$ cells is encouraging and suggests that we may be generating clinically-relevant immune responses and that the immunogenic antigens have been combined with a suitably immunogenic delivery mechanism. DPX-0907 also includes a $\mathrm{T}$ helper epitope that has previously used to augment peptide vaccine immunogenicity [12,25]. Although the focus was to study antigen-specific $\mathrm{CD}^{+} \mathrm{T}$ cells, $\mathrm{CD} 4^{+} \mathrm{T}$ cell responses werea lso detected against the
A16L peptide in vaccinated patients, and these responses correlated with $\mathrm{CD}^{+} \mathrm{T}$ cell responses in the same assay. This suggests that the inclusion of a $\mathrm{T}$ helper peptide may have facilitated the generation of the specific CD8 T cells observed.

All the antigens contained in DPX-0907 are differentially presented by tumor cells [5] and have been validated experimentally $[7,11]$. Atleast three antigens (P4, P5 and P15, representing peptides from topoisomerase IIa (TOP2A), Integrin $\beta 8$-precursor, and EDDR1 respectively) have been demonstrated to be upregulated at the mRNA level in ovarian cancer (unpublished observations). TOP2A (P4) is also associated with rapidly progressing cancers and relatively poor survival while EDDR1 (P15), a protein receptor kinase found to be over-expressed in ovarian cancers, is associated with poor prognosis and overall survival [8,32]. In addition, Tumor necrosis factor-Alpha Converting Enzyme (TACE/ADAM-17, P13) generates soluble epidermal growth factor receptor (EGFR) ligands such as EGF and HB-EGF that have been shown to be important in tumorigenesis [33].

In our study, we detected immune responses to 6 of the 7 immunizing antigens (P3, P4, P5, P7, P13 and P15) contained in DPX-0907. We saw the generation of responses to multiple antigens in several patients by MHC-pentamer and ICS assays and were able to confirm the observed responses by ELISpot in two responding patients. Our analysis also demonstrated pre-existing immune responses to a number of these antigens in our patient population, which suggests that patients' $\mathrm{T}$ cells have been primed against these antigens prior to patient inclusion on this study. This provides further validation that the chosen vaccine epitopes are biologically relevant targets. The HLA-A2 restriction of the vaccine is expected to reduce eligibility of the Caucasian patient population by $50 \%$, however future vaccines could incorporate peptides of other HLA restrictions or more promiscuous peptides to allow for broader utility of the vaccine. The multi-antigen approach is expected to minimize the impact of immune editing of one or more antigens by cancer cells under targeted immune pressure. The impact of possible HLA down-regulation in advanced cancer patients on the activity of this vaccine remains unknown.

Immune responses to DPX-0907 antigens were more frequent in breast and ovarian cancer patients as compared to prostate cancer patients. It is unclear whether this result indicates that ovarian and breast cancer patients are biologically more immune responsive than prostate cancer patients or whether this reflects other confounding clinical factors. We note however that most of the breast and ovarian cancer patients had stable disease or responses to their previous treatment, whereas 
the prostate cancer patients enrolled had progressive disease and increasing PSAs. In addition, all prostate cancer patients entered in this trial had greater than or equal to three previous treatments and demonstrated progression necessitating some other treatment soon after the completion of the three vaccinations. The observed differences between prostate cancer and other patients in this study were not statistically significant due to the small sample size; however, our results indicate that patients with a history of favorable responses to therapy, in a state of minimal residual disease or with fewer previous treatments are likely preferred candidates for treatment with DPX-0907, as has been proposed by others [34].

In summary, we have shown that this novel cancer vaccine - DPX-0907 - employing an innovative liposomal formulation is safe, immunogenic and worthy of further clinical testing. These studies will likely be required to optimize the patient populations treated and potentially incorporate an immune modulator to further optimize the antigen-specific immune responses. Future strategies will explore this and other antigen vaccines utilizing the DepoVax formulation, to generate functionally relevant clinical response able to reduce or eliminate micometastatic disease.

\section{Additional files}

Additional file 1: Figure S1. Clinical protocol outline and dosing schedule of DPX-0907 for the treatment of breast, ovarian and prostate cancer patients. Patients were pre-screened for determining their eligibility to participate in the study and were assigned to dose A or B of vaccine treatment as indicated. Blood samples were collected at prescreening visit, during 3 treatments and at 1, 3 and 6 month posttreatment follow up. Immune monitoring was performed on PBMC from SD0, SD21, SD42 and SD73. Figure S2. Antigenic peptide-induced cytokine secretion by PBMC from DPX-0907 treated breast cancer patients. Patient PBMC were stimulated ex vivo for $6 \mathrm{~h}$ in the presence of pooled peptides included in DPX-0907, and protein transport inhibitor. Cells were surface stained for CD3, CD8, CD27 and CD45RA, permeabilized and stained for intracellular cytokines. Data represent percentage of total $C D 8^{+} T$ cells and/or central memory $\left(T_{C M}\right) C D 8 T$ cells positive for cytokine secretion following peptide stimulation. Figure S3. Representative pentamer staining dot plots from two ovarian (02-09, 05-15) and one prostate cancer patient (01-18) showing increase in antigen-specific CD8 ${ }^{+} \mathrm{T}$ cells post-DPX-0907 treatment as compared to base line (SD0). Patient PBMC were stimulated with indicated peptide, in the presence of cytokines and stained with MHC-pentamer reagents. Cells were collected using a live gate and $\mathrm{CD}^{+}$cells were further separated to $C D 8^{+} T$ cells. These cells were plotted by CD45RA staining versus pentamer positive staining. Data on top left quadrant represent percentage of CD45RA ${ }^{\text {neg/low }}$ activated cells that were stained positive for pentamer reagent prepared using corresponding peptide shown for each patient. Figure S4. DPX-0907 vaccine induces multi-functional T cells capable of secreting multiple cytokines. Pre- and post- treatment PBMC samples from a representative breast (04-06) and ovarian (05-14) cancer patient were stimulated with peptide pool and analyzed by multi-parametric flow cytometry. Simultaneous determination of T cell phenotype (total, $T_{C M}$ ) and type of cytokine secreted (IFN- $\gamma /$ TNF-a/lL-2) was performed using FACS DiVa software (BD Bioscience) and multifunctional cytokine analysis was performed after stringent gating of each cytokine positive population and subsequent Boolean gating with FlowJo software. Figure S5. IFN- $\gamma$ ELISpot responses in DPX-0907-treated breast and ovarian cancer patient PBMC. PBMC from selected breast and ovarian cancer patients and from non-vaccinated female healthy control subjects ( $\mathrm{HC}-1$ and $\mathrm{HC}-2$ ) were used in ELISpot plates to stimulate with individual and pooled DPX-0907 peptides (10, 25, 50 and 100ug/ml tested and $50 \mathrm{\mu g} / \mathrm{ml}$ response shown) as described in the Materials and Methods. Mean \pm SD SFU were plotted from the triplicate wells and expressed per $3 \times 10^{5}$ cells that were plated per well.

Additional file 2: Table S1. Tumor-associated antigens and corresponding peptides included in DPX-0907. Table S2. Patient Demographics. Table S3. Detection of antigen-specific CD8 ${ }^{+} \mathrm{T}$ cells in patients with immune responses to DPX-0907 treatment.

\section{Competing interests}

NLB, MAM, JJN, GC, HK and KO received financial support from Immunovaccine to support the research described in the manuscript. MK, RN, LS, LDM, GMW, MMS and MM are employed by and/or stockholders of Immunovaccine.

\section{Authors' contributions}

NLB and MM participated in the design and coordination of the study, data acquisition and analysis and helped draft the manuscript, MK participated in the coordination of the study, data acquisition, immune data analysis and helped draft the manuscript, RN, MAM, JJN, GC, HK and KO participated in the design of the study, recruitment of patients and helped draft the manuscript, GMW, LS, LDM and MMS participated in the coordination of the study and helped draft the manuscript. All authors gave final approval of the manuscript for publication.

\section{Acknowledgements}

The authors would like to thank Dr. Walter Storkus (Department of Dermatology, University of Pittsburg School of Medicine) for his critical review and valuable comments and edits of the manuscript.

\section{Author details}

'Sunnybrook Health Sciences Center, Toronto, ON, Canada. ${ }^{2}$ Immunovaccine Inc, Halifax, NS, Canada. ${ }^{3}$ Department of Microbiology \& Immunology, Dalhousie University, Halifax, NS, Canada. ${ }^{4}$ Duke Comprehensive Cancer Center, Durham, NC, USA. ${ }^{5}$ Mary Crowley Cancer Research Center, Dallas, TX, USA. ${ }^{6}$ University of Pittsburgh Cancer Institute, Pittsburgh, PA, USA. ${ }^{7}$ Rush University Medical Center, Chicago, IL, USA. ${ }^{8}$ Roswell Park Cancer Institute, Buffalo, NY, USA.

Received: 11 April 2012 Accepted: 11 July 2012

Published: 3 August 2012

\section{References}

1. Madan RA, Arlen PM, Mohebtash M, Hodge JW, Gulley JL: Prostvac-VF: a vector-based vaccine targeting PSA in prostate cancer. Expert Opin Investig Drugs 2009, 18:1001-1011.

2. Small EJ, Schellhammer PF, Higano CS, Redfern $\mathrm{CH}$, Nemunaitis JJ, Valone FH, Verjee SS, Jones LA, Hershberg RM: Placebo-controlled phase III trial of immunologic therapy with sipuleucel-T (APC8015) in patients with metastatic, asymptomatic hormone refractory prostate cancer. J Clin Oncol 2006, 24:3089-3094.

3. Sosman JA, Carrillo C, Urba WJ, Flaherty L, Atkins MB, Clark Jl, Dutcher J, Margolin KA, Mier J, Gollob J, et al: Three phase II cytokine working group trials of gp100 (210 M) peptide plus high-dose interleukin-2 in patients with HLA-A2-positive advanced melanoma. J Clin Oncol 2008, 26:2292-2298.

4. Thompson JA, Hamid O, Minor D, Amin A, Ron IG, Ridolfi R, Assi H, Berman D, Siegel J, Weber JS: Ipilimumab in treatment-naive and previously treated patients with metastatic melanoma: retrospective analysis of efficacy and safety data from a phase II trial. J Immunother 2012, 35:73-77.

5. Ramakrishna V, Ross MM, Petersson M, Gatlin CC, Lyons CE, Miller CL, Myers $H E$, McDaniel M, Karns LR, Kiessling R, et al: Naturally occurring peptides associated with HLA-A2 in ovarian cancer cell lines identified by mass 
spectrometry are targets of HLA-A2-restricted cytotoxic T cells. Int Immunol 2003, 15:751-763.

6. Morse MA, Secord AA, Blackwell K, Hobeika AC, Sinnathamby G, Osada T, Hafner J, Philip M, Clay TM, Lyerly HK, Philip R: MHC class I-presented tumor antigens identified in ovarian cancer by immunoproteomic analysis are targets for T-cell responses against breast and ovarian cancer. Clin Cancer Res 2011, 17:3408-3419.

7. Sinnathamby G, Zerfass J, Hafner J, Block P, Nickens Z, Hobeika A, Secord AA, Lyerly HK, Morse MA, Philip R: ADAM metallopeptidase domain 17 (ADAM17) is naturally processed through major histocompatibility complex (MHC) class I molecules and is a potential immunotherapeutic target in breast, ovarian and prostate cancers. Clin Exp Immunol 2011, 163:324-332.

8. Sinnathamby G, Zerfass J, Hafner J, Block P, Nickens Z, Hobeika A, Secord AA, Lyerly HK, Morse MA, Philip R: EDDR1 is a Potential Immunotherapeutic Antigen in OVarian, Breast, and Prostate Cancer. Cell Immunol: J Clin; 2011:2

9. Hanahan D, Weinberg RA: The hallmarks of cancer. Cell 2000, 100:57-70.

10. Pilla L, Rivoltini L, Patuzzo R, Marrari A, Valdagni R, Parmiani G: Multipeptide vaccination in cancer patients. Expert Opin Biol Ther 2009, 9:1043-1055.

11. Karkada M, Weir GM, Quinton T, Sammatur L, MacDonald LD, Grant A, Liwski R, Juskevicius R, Sinnathamby G, Philip R, Mansour M: A novel breast/ ovarian cancer peptide vaccine platform that promotes specific type-1 but not Treg/Tr1-type responses. J Immunother 2010, 33:250-261.

12. Slingluff $\mathrm{CL}$ Jr, Yamshchikov G, Neese P, Galavotti H, Eastham S, Engelhard VH, Kittlesen D, Deacon D, Hibbitts S, Grosh WW, et al: Phase I trial of a melanoma vaccine with gp100(280-288) peptide and tetanus helper peptide in adjuvant: immunologic and clinical outcomes. Clin Cancer Res 2001, 7:3012-3024.

13. Daftarian P, Mansour M, Benoit AC, Pohajdak B, Hoskin DW, Brown RG, Kast WM: Eradication of established HPV 16-expressing tumors by a single administration of a vaccine composed of a liposome-encapsulated CTL-T helper fusion peptide in a water-in-oil emulsion. Vaccine 2006, 24:5235-5244

14. Daftarian PM, Mansour M, Pohajdak B, Fuentes-Ortega A, Korets-Smith E, Macdonald L, Weir G, Brown RG, Kast WM: Rejection of large HPV-16 expressing tumors in aged mice by a single immunization of VacciMax encapsulated CTL/T helper peptides. J Trans/ Med 2007, 5:26.

15. Mansour M, Pohajdak B, Kast WM, Fuentes-Ortega A, Korets-Smith E, Weir GM, Brown RG, Daftarian P: Therapy of established B16-F10 melanoma tumors by a single vaccination of $\mathrm{CTL} / \mathrm{T}$ helper peptides in VacciMax. J Transl Med 2007, 5:20.

16. Penwell A, Sharp K, Mansour M, Sammatur L: Development and validation of an HPLC/UV assay for separation and quantification of peptide antigens from a liposomal vaccine delivery platform. J Pharm Biomed Anal 2012,66:176-182.

17. Takahashi N, Ohkuri T, Homma S, Ohtake J, Wakita D, Togashi Y, Kitamura H, Todo S, Nishimura T: First clinical trial of cancer vaccine therapy with artificially synthesized helper/ killer-hybrid epitope long peptide of MAGE-A4 cancer antigen. Cancer Sci 2012, 103:150-153.

18. Chiang $C L$, Kandalaft LE, Coukos G: Adjuvants for enhancing the immunogenicity of whole tumor cell vaccines. Int Rev Immunol 2012, 30:150-182

19. Jager $E$, Jager $D$, Knuth $A$ : Antigen-specific immunotherapy and cancer vaccines. Int J Cancer 2003, 106:817-820.

20. Disis ML, Schiffman K, Guthrie K, Salazar LG, Knutson KL, Goodell V, dela Rosa C, Cheever MA: Effect of dose on immune response in patients vaccinated with an her-2/neu intracellular domain protein--based vaccine. J Clin Oncol 2004, 22:1916-1925.

21. Perales MA, Yuan J, Powel S, Gallardo HF, Rasalan TS, Gonzalez C, Manukian G, Wang J, Zhang Y, Chapman PB, et al: Phase I/II study of GM-CSF DNA as an adjuvant for a multipeptide cancer vaccine in patients with advanced melanoma. Mol Ther 2008, 16:2022-2029.

22. van Driel WJ, Ressing ME, Kenter GG, Brandt RM, Krul EJ, van Rossum AB, Schuuring E, Offringa R, Bauknecht T, Tamm-Hermelink A, et al: Vaccination with HPV16 peptides of patients with advanced cervical carcinoma: clinical evaluation of a phase I-II trial. Eur J Cancer 1999, 35:946-952.

23. Bernhardt SL, Gjertsen MK, Trachsel S, Moller M, Eriksen JA, Meo M, Buanes T, Gaudernack G: Telomerase peptide vaccination of patients with non-resectable pancreatic cancer: A dose escalating phase I/II study. $\mathrm{Br} J$ Cancer 2006, 95:1474-1482
24. Holmes JP, Benavides LC, Gates JD, Carmichael MG, Hueman MT, Mittendorf EA, Murray $J$, Amin A, Craig D, von Hofe E, et al: Results of the first phase I clinical trial of the novel II-key hybrid preventive HER-2/neu peptide (AE37) vaccine. J Clin Oncol 2008, 26:3426-3433.

25. Chianese-Bullock KA, Irvin WP Jr, Petroni GR, Murphy C, Smolkin M, Olson WC, Coleman E, Boerner SA, Nail CJ, Neese PY, et al: A multipeptide vaccine is safe and elicits $T$-cell responses in participants with advanced stage ovarian cancer. J Immunother 2008, 31:420-430.

26. Diefenbach CS, Gnjatic S, Sabbatini P, Aghajanian C, Hensley ML, Spriggs DR, lasonos A, Lee H, Dupont B, Pezzulli S, et al: Safety and immunogenicity study of NY-ESO-1b peptide and montanide ISA-51 vaccination of patients with epithelial ovarian cancer in high-risk first remission. Clin Cancer Res 2008, 14:2740-2748

27. Odunsi K, Qian F, Matsuzaki J, Mhawech-Fauceglia P, Andrews C, Hoffman EW, Pan L, Ritter G, Villella J, Thomas B, et al: Vaccination with an NY-ESO-1 peptide of HLA class $\mathrm{I} / \mathrm{II}$ specificities induces integrated humoral and $\mathrm{T}$ cell responses in ovarian cancer. Proc Natl Acad Sci U S A 2007, 104:12837-12842.

28. Faul EJ, Aye PP, Papaneri AB, Pahar B, McGettigan JP, Schiro F, Chervoneva I, Montefiori DC, Lackner AA, Schnell MJ: Rabies virus-based vaccines elicit neutralizing antibodies, poly-functional CD8+ T cell, and protect rhesus macaques from AIDS-like disease after SIV(mac251) challenge. Vaccine 2009, 28:299-308.

29. Wolfl M, Merker K, Morbach H, Van Gool SW, Eyrich M, Greenberg PD, Schlegel PG: Primed tumor-reactive multifunctional CD62L+ human CD8+ T cells for immunotherapy. Cancer Immunol Immunother 2011, 60:173-186

30. Almeida JR, Sauce D, Price DA, Papagno L, Shin SY, Moris A, Larsen M, Pancino G, Douek DC, Autran B, et al: Antigen sensitivity is a major determinant of CD8+ T-cell polyfunctionality and HIV-suppressive activity. Blood 2009, 113:6351-6360.

31. Almeida JR, Price DA, Papagno L, Arkoub ZA, Sauce D, Bornstein E, Asher TE, Samri A, Schnuriger A, Theodorou I, et al: Superior control of HIV-1 replication by CD8+ T cells is reflected by their avidity, polyfunctionality, and clonal turnover. J Exp Med 2007, 204:2473-2485.

32. Heinzelmann-Schwarz VA, Gardiner-Garden M, Henshall SM, Scurry J, Scolyer RA, Davies MJ, Heinzelmann M, Kalish LH, Bali A, Kench JG, et al: Overexpression of the cell adhesion molecules DDR1, Claudin 3, and Ep-CAM in metaplastic ovarian epithelium and ovarian cancer. Clin Cancer Res 2004, 10:4427-4436.

33. Merchant NB, Voskresensky I, Rogers CM, Lafleur B, Dempsey PJ, Graves-Deal R, Revetta F, Foutch AC, Rothenberg ML, Washington MK, Coffey RJ: TACE/ ADAM-17: a component of the epidermal growth factor receptor axis and a promising therapeutic target in colorectal cancer. Clin Cancer Res 2008, 14:1182-1191.

34. Spisek R: Immunoprevention of cancer: time to reconsider timing of vaccination against cancer. Expert Rev Anticancer Ther 2006, 6:1689-1691.

\section{doi:10.1186/1479-5876-10-156}

Cite this article as: Berinstein et al:: First-in-man application of a novel therapeutic cancer vaccine formulation with the capacity to induce multi-functional T cell responses in ovarian, breast and prostate cancer patients. Journal of Translational Medicine 2012 10:156.

\section{Submit your next manuscript to BioMed Central and take full advantage of:}

- Convenient online submission

- Thorough peer review

- No space constraints or color figure charges

- Immediate publication on acceptance

- Inclusion in PubMed, CAS, Scopus and Google Scholar

- Research which is freely available for redistribution 